\title{
Chapter 7 \\ Inuit Nunangat and the Northwest \\ Passage: An Exploration of Inuit and Arctic Shipping Conceptualizations of and Relationships with Arctic Marine Spaces in Canada
}

\section{Leah Beveridge}

\begin{abstract}
Historically, Inuit have not been participants in the governance of Arctic shipping, but efforts are underway to better account for their concerns with regard to the operations of vessels in their waters through partnerships and other forms of collaboration. To understand and address these concerns, there is a need to understand and appreciate the worldview within which they are based. To support crosscultural dialogue on shipping matters, this chapter will discuss the worldview of Inuit and the worldviews that are implicit in the governance of Arctic shipping, as well as the challenges of and opportunities for integrating the two. By bringing the ethnographic and anthropological literature on Inuit worldviews into a discussion of shipping governance, this chapter offers insights for cross-cultural collaborations between Inuit and non-Inuit working on matters of Arctic shipping governance in Canada.
\end{abstract}

Keywords Arctic $\cdot$ Arctic shipping $\cdot$ Canada $\cdot$ Inuit $\cdot$ Marine space $\cdot$ Sea ice $\cdot$ Shipping governance

\subsection{Introduction}

Historically, Arctic voyages were figments of the imagination for most and reality for only a few. Even until recently, maritime activities have been minimal, with the majority of traffic in Canadian Arctic waters being associated with community

L. Beveridge (四)

Marine Affairs Program, Dalhousie University, Halifax, Canada

e-mail: leah.beveridge@dal.ca 
resupply and mining projects. However, with changing environmental conditions, advancing technology, and a drive to explore and exploit new frontiers, commercial shipping across the circumpolar Arctic is growing. The greatest expansions seen in the Canadian North have been in the marine tourism sector, a trend that is expected to continue along with other forms of destinational traffic including the servicing of communities, mines, and, if permitted in the future, offshore oil and gas ${ }^{1}$ (e.g., Lasserre and Pelletier 2011; Pizzolato et al. 2013). The governance of such Arctic shipping is a "complicated mosaic" (Arctic Council 2009, 50), which Inuit have not historically participated in. However, the Government of Canada has undertaken to better account for the concerns of Inuit with regard to the operations of vessels in their waters by collaborating with them, namely through the Low Impact Shipping Corridors and the Oceans Protection Plan, and by focusing on partnerships and the inclusion of Inuit knowledge.

Each and every person has a worldview: a set of underlying, intrinsic, and subconscious assumptions about the world. When someone speaks, the meaning of their words is tied to their worldview (Ingold 2000), which is particularly important to acknowledge when engaging across worldviews. If the differing points of departure are not acknowledged and/or respected, there is the risk that although the words used by the two interlocutors are the same, the meaning behind them may be different (Viveiros de Castro 2004). Therefore, to effectively communicate, collaborate, and partner with Inuit on matters of Arctic shipping governance, there must not only be the forums to speak to one another but also the willingness and commitment to understand the worldview of those involved in the dialogue so that the true meaning of their words can be understood. This subsequently demands an acknowledgement that the worldview of Inuit is an equally legitimate way of knowing and being in the world to that of shipping governance.

This chapter will discuss the worldview of Inuit and the worldviews that are implicit in the governance of Arctic shipping and the challenges of and opportunities for integrating the two. Herein, "shipping" will refer to vessels resupplying communities and mines and transporting bulk cargo and will not include fishing vessels, passenger (cruise) vessels, or pleasure craft. It is important to note at the onset that the understanding, articulation, and engagement with the Inuit worldview outlined in this chapter is based on a review of ethnographic and anthropological literature, supplemented with the author's own experiences. It does not attempt to speak on behalf of Inuit, but rather intends to bring literature on Inuit worldviews into a discussion of shipping governance, offering insights for cross-cultural collaborations between Inuit and non-Inuit working on shipping issues and opportunities in Canada's North.

\footnotetext{
${ }^{1}$ A moratorium on offshore oil and gas development in Canadian Arctic waters was established in 2016 and will be reviewed every 5 years (Office of the Prime Minister 2016).
} 


\subsection{Governance of Arctic Shipping}

The governance of Arctic shipping consists of interacting and interdependent instruments and decisions at the international, regional, domestic, and subnational scales, rooted in what will be referred to here as a "shipping governance worldview". Like any other, this worldview has its own belief system, inclusive of knowledge and the subconscious processes for thinking about and perceiving the world (Blaser 2009; Laidler 2007; Sable et al. 2006; Stephenson and Moller 2009; Trippett 2000). Insights into how shipping governance views the world can be drawn from the fields of geography (Bennett et al. 2016; Heyes 2007; Steinberg 1999) and anthropology (Aporta 2011; Ingold 2000; Tyrrell 2005; Whitridge 2004), as well as the key instruments of the governance regime itself.

The shipping governance worldview is rooted in a naturalist ontology, meaning there is an understanding that nature and culture can be divided (Blaser 2009; Ingold 2000); people are placed outside rather than alongside nature, that is, the marine environment. The United Nations Convention on the Law of the Sea (UNCLOS) positions nature - the marine environment - as something to be used by people, believing that through clear rules for this use, peaceful international relations and economic, social, and sustainable development can be achieved (UNCLOS 1982, Preamble). It acknowledges that marine issues (e.g., with respect to fishing, shipping, marine conservation, scientific research) are interrelated but introduces a number of divisions to support legal order for the seas and oceans. One inherent division underlying UNCLOS is that the land is separate from the sea, wherein the boundary lies at the low-water mark (Article 5). UNCLOS further subdivides ocean space into zones based on distances from this boundary and defines jurisdictions for marine management within each. Responsibility for managing various aspects (e.g., fishing, shipping, conservation, research) within the zones is also divided. These divisions, together with the understanding that the space and its issues are interconnected, demonstrate that there is an understanding that the whole can be rebuilt through a compilation of all the pieces.

Under UNCLOS, matters of international shipping are assigned to the "competent international organization", which is understood to be the International Maritime Organization (IMO). The IMO is a specialized agency of the United Nations that sets global standards for the safety, security, and environmental performance of international shipping. It has established a comprehensive regulatory framework that is universally adopted and uniformly implemented by its member states. The mechanisms through which the various topics of its work (e.g., safety of life at sea, protection of the marine environment, and training and certification) are advanced are divided across committees and subcommittees and implemented through a number of conventions, codes, and other standards.

A member state is expected to implement the IMO instruments to which it is a party within their jurisdiction, as defined by UNCLOS. In Canada, Transport Canada is the main department responsible for implementing IMO instruments to which Canada is a party and for regulating shipping activities in its waters; that is, 
it is Canada's maritime administration. The main mechanism through which this is achieved is the Canada Shipping Act, 2001 (CSA 2001), supported by various other maritime statutes, such as the Canadian Navigable Waters Act (1985; formerly the Navigation Protection Act). Environmental statutes also establish offences applicable to shipping, including the Canadian Environmental Protection Act (1999), the Oceans Act (1996), and the Migratory Birds Convention Act (1994). This regulatory regime recognizes the relationship between shipping and other ocean matters, such as those in the Oceans Act (e.g., fishing, conservation).

Under UNCLOS, within the IMO, and by Canada, there is recognition that there is a divide between the Arctic and the rest of the global ocean, including southern Canadian waters, due to its unique environmental sensitivities and operational requirements for ships. This is reflected in Article 234 of UNCLOS, which provides states the authority to develop "laws and regulations for the prevention, reduction and control of marine pollution from vessels in ice-covered areas within the limits of [their] exclusive economic zone"; in the establishment of the International Code for Ships Operating in Polar Waters (the Polar Code 2014/2015), which addresses the aspects of safety of navigation, seafarer training, and marine environmental protection that are specific to the polar regions; and in the Canadian Arctic Waters Pollution Prevention Act (AWPPA 1970), which focuses on the safety of navigation and marine environmental protection and predates both UNCLOS and the Polar Code. Canada further subdivides its Arctic waters by historical ice regimes with the zone/date system, which is laid out in the Shipping Safety Control Zones Order (see Chap. 15 in this volume).

One of the key operational requirements for ships in Arctic waters is the need to cope with the presence of sea ice, which is a risk to ships and a barrier to marine transportation (Lasserre et al. 2016). Sea ice also introduces the need to be flexible and adaptable within an otherwise rigid regime. This has been achieved through the Polar Operational Limit Assessment Risk Indexing System (POLARIS) and the Arctic Ice Regime Shipping System (AIRSS) (Transport Canada 2018). These systems assess the risk posed by various ice conditions to a vessel based on its construction. Risk assessments are conducted throughout the duration of a voyage, and if it is determined that the pre-planned voyage will take a vessel through ice conditions outside its operational limits (i.e., unsafe conditions), the vessel is required to adapt its voyage plan to ensure the safety of navigation. This could mean taking a longer route, waiting for sea ice conditions to become lighter, or cancelling a voyage altogether. Sea ice thus represents not only a safety risk to vessels but a financial risk, as delays in transportation mean extra costs in fuel, wages, and sometimes penalties for late deliveries (Lasserre et al. 2016). The unpredictability introduced by the Arctic environment, namely sea ice, was found by Lasserre et al. (2016) to be the second most-cited operational challenge by shipping companies around the world; the environmental conditions more broadly were the most-cited.

In addition to the regulatory regime, there are a number of domestic policies and programs targeting the safety and environmental considerations of navigating in Canadian Arctic waters. One of the key programs is the Low Impact Shipping Corridors (the Corridors) initiative, which is co-led by the Canadian Coast Guard 
and Transport Canada. The aim of the Corridors is to inform the prioritization of federal investments in the northern marine transportation system and to develop a collaborative governance framework in partnership with Inuit (Chénier et al. 2017). The work on the Corridors is supported and complemented by the Oceans Protection Plan (OPP), which aims to develop a world-leading marine safety system, to preserve and restore marine ecosystems, to establish a stronger evidence base for decision-making, and to strengthen Indigenous partnerships (Government of Canada 2019). The implementation of the OPP is divided across a number of initiatives, with the understanding that, together, they will achieve the overarching goals of the Plan. Some of the initiatives that will contribute to the Corridors include investments in basic marine infrastructure, training programs, expanding Canadian Coast Guard Auxiliaries, and enhancing community search and rescue and environmental response capabilities. Other initiatives are exploring alternative approaches to decision-making regarding ship operations; for example, the Proactive Vessel Management initiative is providing the space for the Government of Canada and Indigenous peoples and coastal communities to explore solutions to marine issues and conflicts pertaining to shipping through six pilot projects across Canada, including one with Inuit in the Canadian Arctic (Transport Canada 2019a).

Although the regulatory framework of the Arctic shipping governance regime focuses on nature (safety, environmental protection), it is beginning to be recognized that culture is integrated with nature in Arctic marine spaces in particular. For example, in the "Methodology to Analyse Impacts of a Ban on the Use and Carriage of Heavy Fuel Oil as Fuel by Ships in Arctic Waters" developed by the Prevention, Preparedness and Response Subcommittee of the IMO, it is recommended that the "subsistence culture and lifestyle of Arctic indigenous and local communities" be taken into consideration when trying to understand the potential impacts of banning the use of heavy fuel oil by ships in the Arctic (PPR 2019, para 13). It is understood in the Methodology that subsistence is not simply a monetary matter or one of food security but that "subsistence activities are integrated more broadly in a cultural sense as an aspect of the underpinnings of social cohesion, language, public health and identity" (PPR 2019, para. 14).

Furthermore, the individuals that work in the governance and industry of shipping that regularly work on the ground and the waters may have different conceptualizations of marine spaces and the North than the regime itself. For example, Tyrell (2005) speaks of her own engagement and experience with the marine environment, and Steinberg and Peters note that "those who actually engage the ocean, like sailors ... become one with the waves as the waves become one with them, in a blend of complementarity and opposition" $(2015,251)$. Heyes further suggests that for mariners and sailors in particular, the sea is "a domain comprised of divergent spaces [with] real and fanciful stories, memories, mythologies, events and placenames" $(2007,91)$. At the same time, though, there are many who within the shipping governance regime and Canada's maritime administration who have not been and are not actively or consistently interacting with marine spaces and even fewer with Northern places, for example, those working in Ottawa (Transport Canada 
headquarters), Winnipeg, and Edmonton (Transport Canada Prairie and Northern Region offices); that is, non-coastal and non-northern cities. Thus, it is far less likely these individuals would have the same conceptualization or relationship with the North or even marine spaces generally (Laidler 2006).

\subsection{Inuit and Marine Spaces}

Whereas the shipping governance worldview is based in a naturalist ontology, Inuit, like many other Indigenous peoples, have a worldview rooted in an animist or relational ontology (Blaser 2009; Heyes 2007). Through this lens, there is no natureculture divide; people are not separated from the natural world, but rather all aspects of life are intertwined, with people a part of a network (Aporta 2002, 2010, 2011; Dowsley 2015; Ingold 2000; Tester and Irniq 2008; Tyrrell 2005). The relationships within this network are social, non-dominant, and respectful, as opposed to hierarchical wherein people are to use and manage the marine environment (Dowsley 2015; Ingold 2000; Laidler 2006, 2007). Furthermore, the network is holistic, extending beyond the environmental, geophysical, and biological features that often define disciplinary notions of marine spaces. In contrast, the world cannot be divided into such parts, subsequently meaning that it cannot be constructed because there are no parts to assemble (Ingold 2000; Tester and Irniq 2008). In their study of the historical and cultural context of Inuit knowledge, Tester and Irniq (2008) argued that the term "holistic" was not appropriate for describing the Inuit worldview because it represents exactly this concept of compiling pieces to form a whole. Instead, they offer the terms "seamless" or "avaluqanngittuq" (Inuktitut for "that which has no circle or border around it") as better options because it reflects the lack of boundaries that exist within the Inuit worldview. To contrast with "holistic", this chapter will adopt the term "wholistic", which was first heard by the author at an event in Halifax, Nova Scotia by Albert Marshall, a Mi'kmaw Elder (March 2017), ${ }^{2}$ to represent this conceptualization of the indivisible whole of the world.

The seamless, borderless, and "whole" world within which Inuit are a part includes not only marine spaces but land as well. There are some authors who suggest there is a conceptual division between land and sea in the Inuit worldview, even if the worldview embraces continuity from one to the other. Heyes (2007), for example, found that the people of Kangiqsualujjuaq, a community in Nunavik (northern Quebec), see a division due to different terminology associated with land and sea. Tyrrell (2005) also noted that there is an understanding by Inuit of a functional boundary between land and sea, particularly when sea ice is not present. However, when sea ice is present, the "boundary" of the shoreline is blurred and the Arctic transforms into a network of trails that join the land to the sea (Aporta 2009),

\footnotetext{
${ }^{2}$ There are examples of the use of "wholistic" outside an Indigenous perspective; according to the Merriam-Webster online dictionary, the term dates back to the 1920s philosophy.
} 
connecting people with places and each other (e.g., Aporta 2011; Laidler 2007). The sea ice becomes home to Inuit (Aporta 2011), which expands and contracts as the sea ice develops and recedes (Heyes 2007; Tyrrell 2005). Aporta et al. (2018) suggest that the coastline thus be considered a continuum across the land-sea interface, rather than a dividing boundary, which better reflects the notion that the "land" is a single comprehensive whole, while also reflecting that there is a functional distinction between terrestrial and marine spaces. To support a discussion of the governance of Arctic shipping, an industry that only exists in the marine domain, I will proceed with an understanding that a division does exist between the land and the sea while also recognizing that within the Inuit worldview, marine spaces cannot be considered in complete isolation from the land.

The animist or relational ontology also aligns with Ingold's dwelling perspective. In exploring hunter-gatherer cultures, Ingold (2000) describes a dwelling perspective as a worldview wherein one comes to know the world by engaging with it. Given the wholistic nature of the Inuit worldview, this requires attention to the whole of the world through ongoing interactions with it and the active application of knowledge within it (Heyes 2007; Tyrrell 2005; Wisniewski 2010). Gibson (1979, as cited in Ingold 2000, 22) refers to this type of knowledge as borne of an "education of attention". Through a lifelong learning process, one is trained to be attentive and attuned to particular aspects of the world, depending on the activities with which the individual is engaged. Knowledge is not something one gains, stores, and transmits, it is discovered and lived through everyday practices; it is a process rather than a transaction. Inuit knowledge is therefore best understood as a way of being in the world (Rasing 2017; Tester and Irniq 2008) and subsequently is as much about being "Inuk" as it is about what one knows (Dowsley 2015; Searles 2009, 2010; Tyrrell 2005; Whitridge 2004).

"The interaction between people and their places is a lifelong conversation" (Tyrrell 2005, 118) that is personal (Laidler 2006) and intimate (Kielsen Holm 2010) and "brings many memories and emotions that tie people to the place and to each other" (Dowsley 2015, 543). A "place" is not static, nor is it something one can come to know everything about. Rather, it is dynamic and alive, changing in tandem with the rest of the wholistic environment (Aporta et al. 2018; Heyes 2007; Tyrrell 2005). Those who have discovered their world through the "lifelong conversation" of learning through an education of attention can come to predict these changes by understanding the relationality within the ever-changing world around them. For Inuit, the changes, or seasons, can be understood in the ebbs and flows of environmental conditions, with the formation and break-up of sea ice, the changes in animal distribution and behaviour, and subsequently the sequence of harvesting playing important roles (Laidler 2006; Wisniewski 2010). These seasons are closely associated with Inuit identity and the daily activities that make up the patterns of life (Aporta et al. 2018; Laidler 2006, 2007; Tyrrell 2005).

A key part of Inuit life is travel across the network of trails the sea ice reveals, be it to reach hunting grounds or to visit family and friends. But traveling is not simply a matter of moving from one location to another. The act of the journey itself, the movement along the trail, is an equally important facet of interacting with "home" (and thus discovering knowledge and being Inuk) as is the act of hunting or sharing 
the harvest or visiting with family and friends. These trails are not the static lines they are depicted to be through traditional cartographic methods, for this network unfolds across the landscape over time "just like musical performance" (Ingold 2000, 238). Just as with music, it is the movement from one place to the next, measured in time rather than space, that produces the meaning and significance of a trail. Through active engagement with the trail and the practice of applying knowledge along it (an education of attention), one develops a deeper understanding of and relationship with the wholistic world, which is often reflected in the richness and level of detail in the associated vocabulary. For example, Inuit have a vast vocabulary relating to sea ice, which demonstrates the importance of being able to describe the conditions and the functional implications of such detailed knowledge for travel and hunting (Huntington et al. 2010; Ingold 2000; Krupnik et al. 2010; Wisniewski 2010). Through this process, the trail becomes a journey, one that encompasses places, movements, memories, events, and social connections (Aporta 2002, 2004, 2009, 2011; Heyes 2007; Laidler 2007; Tyrrell 2005; Whitridge 2004).

Some authors have found the relationship between Inuit, particularly younger generations (Aporta 2004; Bennett et al. 2016), and the world to be changing. For example, Aporta and MacDonald (2011) found that distance of travel is described by some Inuit today less in terms of time and more so by the number of tanks of fuel required to traverse the distance by skidoo. Rasing (2017) also wrote of the changes in the relationship between Inuit and the environment as a result of the shift from the semi-nomadic lifestyle of living on the land to the more sedentary lifestyle of living in communities. Trippett (2000), however, understands these changes as examples of the close and dynamic relationship between all facets of life, including between Inuit and the land (Aporta and Higgs 2005; Dowsley 2015). Therefore, although the manifestation of the relationship and conceptualization of spaces may be changing, the existence and importance of the relationship may not necessarily be diminishing.

\subsection{Implications of Considering Inuit and Shipping Worldviews for Shipping Governance}

To reflect an Inuit worldview, the Arctic can be articulated as "Inuit Nunangat", meaning homeland, all-encompassing of the land, water, and ice, and the interrelationships within that embodies the concept of "home". From a shipping governance worldview, the Arctic can be understood as the "Northwest Passage", signifying the space as one for transportation and trade and embodying the geographic aspects that delineate a way through the Arctic Archipelago. The Northwest Passage represents a conception of space defined by the boundaries of maritime zones according to UNCLOS, the Polar Code, the AWPPA, and the Shipping Safety Control Zones Order.

\footnotetext{
${ }^{3}$ The Northwest Passage(s) only represents a component of Canadian Arctic waters-those that serve as transportation routes through the Arctic Archipelago-but here will represent Arctic marine spaces in Canada as a whole.
} 
To begin to integrate the conceptualizations of the Arctic as Inuit Nunangat and the Northwest Passage would be to recognize that in the former, the elements that comprise the whole of the world cannot be isolated from one another, whereas in the latter, the ability to divide space, topic, and jurisdiction is a central tenant. Consequently, this would mean that discussions of marine issues (as it has been accepted that a division can exist between land and sea), cannot be focused on shipping alone, no matter how comprehensive the approach to the discussion. Inuit relationships to marine spaces cannot be understood in isolation, but by trying to have conversations on only shipping matters, they are being asked to isolate their concerns, that is, to create divides, circles, and borders around particular items within their conceptualization of the space as "home". The difference between wholistic and holistic thus represents a key challenge to integrating shipping governance with Inuit approaches, though it does not make it an impossible feat. Krupnik et al. (2010), for example, demonstrate that endeavours can be successful at bridging across the holistic and wholistic divide through their SIKU Project, an interdisciplinary and comprehensive study of the relationship between Inuit and sea ice. A key piece of this body of work is the participation and involvement of Inuit throughout.

For Transport Canada to encompass a wholistic approach would require the Department to consider far more than transportation policies and programs for the purpose of an efficient, clean, safe, and secure transportation system (Transport Canada 2017). For example, it would require greater consideration of marine biology and ecology (the mandate of Fisheries and Oceans Canada and Environment and Climate Change Canada) and natural resource development (Natural Resources Canada). It would also require considerations of "culture", for example, health and social and cultural well-being (Crown-Indigenous Relations and Northern Affairs Canada). Sea ice complicates this further by physically being of water and functionally being of land (Steinberg and Peters 2015) and furthermore by only being present for part of the year.

An alternative to the expansion of the mandate of a single department would be significantly greater interdepartmental collaboration. Support for such an approach can be found in UNCLOS, which recognizes that "the problems of ocean space are closely interrelated and need to be considered as a whole" (Preamble), as well as policies of the federal government, including the 2002 Oceans Strategy, which calls for integrated management, and, more recently, through the Oceans Protection Plan and its whole-of-government approach. Greater coordination of efforts within the Government of Canada would represent a holistic approach but would still be challenged by the concept of wholism. Not only is it based on an assumption that the summation of the parts (departments) produces the whole, but it does not and arguably cannot reflect the relationship Inuit have with marine spaces and the sea ice built on lifetimes of engaging with their home without their participation.

The sea ice is subject to particularly polarizing views between Inuit and the existing shipping governance regime. As a part of Inuit Nunangat, sea ice is a feature of home and one that expands territory, allowing for greater mobility and supporting the practice of living. In contrast, in the context of the Northwest Passage, it is an inhibitor of transit, a dangerous inanimate feature of Arctic navigation that 
represents a significant financial and operational risk (Aporta 2011; Bravo 2010; Lasserre et al. 2016; Tyrrell 2005). These opposing conceptualizations of ice and interactions with it—one living through engaging with it and the other conducting business through destroying or avoiding it—create a conflict between the freedom of mobility and the freedom of navigation. However, the emphasis on the risk posed by the sea ice in the shipping governance regime also represents a certain degree of respect for the feature. Although it may not be envisioned as "alive" as it is in the Inuit worldview, it is recognized as dynamic and outside the control of people. It has led the otherwise rigid shipping governance regime to adapt to provide flexibility through the zone/date system, AIRSS and POLARIS.

Flexibility in the management of ship traffic is also appearing elsewhere in Canada. For example, Transport Canada has introduced dynamic speed restrictions on traffic in the Gulf of St. Lawrence for the purpose of protecting the North Atlantic right whale. When the Government of Canada determines a whale is present in defined "dynamic zones", vessels over $13 \mathrm{~m}$ in length must reduce their speed (Transport Canada 2019b). This demonstrates a more general recognition that the world is dynamic, and therefore so too must be the approaches to shipping governance. This, in turn, opens the door for cross-cultural conversations about adaptability and flexibility based on a shared understanding that the world is ever-changing.

\subsection{Conclusion}

This chapter set out to support cross-cultural dialogues on matters of Arctic shipping governance through a discussion of the worldview of Inuit and the worldviews implicit in the governance of Arctic shipping, as well as the challenges of and opportunities for integrating the two. The conception of this work was the recognition that words come from a worldview, and subsequently there is a requirement to acknowledge and respect the worldview of Inuit if their concerns are to be truly heard and considered.

The Inuit worldview can be understood as conceptualizing Arctic marine spaces as part of Inuit Nunangat - their homeland - inclusive of the land, water, sea ice, and all facets of life. The shipping governance worldview, in contrast, conceptualizes Arctic marine spaces as the Northwest Passage, dividing nature from culture and further separating nature into jurisdictions and responsibilities that isolate facets of life from one another. Through efforts such as the Oceans Protection Plan's whole-of-government approach, the shipping governance regime is moving towards a holistic approach by advancing interdepartmental and multi-stakeholder collaboration. Inuit, though, have a wholistic worldview, which is premised on the notion that the world cannot be subdivided and isolated into parts, meaning it also cannot be reconstructed. The differences between a holistic and wholistic approach are not a barrier to collaboration and partnership but do need to be taken into consideration when working cross-culturally.

Although the Inuit and shipping governance worldviews do demonstrate differences, to state that all those involved in the shipping governance regime hold this same 
conceptualization of Arctic and/or marine spaces is to miss a potential opportunity, for just as "the cognized landscape of the Inuit was not less precise or rational for the immense cultural burden it bore, [neither are] Western geographies devoid of fantasy, emotion, and other subtexts" (Whitridge 2004, 228). Although unlikely to understand Arctic marine spaces as Inuit Nunangat (unless they are Inuk or spent significant time in the North with Inuit), there are individuals working within the regime that have come to know the Arctic and/or marine spaces through their own active engagement with the space. By leveraging the personal experiences of these individuals whom have discovered knowledge through interacting with the world, it is more likely that mutual understanding and respect of worldviews can be found and fostered. Such a foundation will support an understanding of the words spoken by Inuit and subsequently the consideration of Inuit concerns and interests with respect to shipping.

\section{References}

Aporta, C. (2002). Life on the ice: Understanding the codes of a changing environment. Polar Record, 38(207), 341-354.

Aporta, C. (2004). Routes, trails and tracks: Trail breaking among the Inuit of Igloolik. Études/ Inuit/Studies, 28(2), 9-38.

Aporta, C. (2009). The trail as home: Inuit and their pan-Arctic network of routes. Human Ecology, $37,131-146$.

Aporta, C. (2010). The sea, the land, the coast, and the winds: Understanding Inuit Sea ice use in context. In I. Krupnik, C. Aporta, S. Gearheard, G. J. Laidler, \& L. Kielsen Holm (Eds.), Siku: Knowing our ice (pp. 163-180). New York: Springer.

Aporta, C. (2011). Shifting perspectives on shifting ice: Documenting and representing Inuit use of the sea ice. The Canadian Geographer, 55(1), 6-19.

Aporta, C., \& Higgs, E. (2005). Satellite culture global positioning systems, Inuit wayfinding, and the need for a new account of technology. Current Anthropology, 46(5), 729-753.

Aporta, C., \& MacDonald, J. (2011). An elder on sea ice: An interview with Aipilik Inuksuk of Igloolik, Nunavut. Canadian Geographer, 55(1), 32-35.

Aporta, C., Kane, S. C., \& Chircop, A. (2018). Shipping corridors through the Inuit homeland. Limn 10.

Arctic Council. (2009). Arctic marine shipping assessment 2009 report. Troms $\varnothing$ : Arctic Council.

AWPPA. (1970). Arctic Waters Pollution Prevention Act, RSC 1985 c A-12 (Canada).

Bennett, M. M., Greaves, W., Riedlsperger, R., \& Botella, A. (2016). Articulating the Arctic: Contrasting state and Inuit maps of the Canadian north. Polar Record, 52(267), 630-644.

Blaser, M. (2009). Political ontology: Cultural studies without "cultures"? Cultural Studies, 23(5-6), 873-896.

Bravo, M. T. (2010). Epilogue: The humanism of sea ice. In I. Krupnik, C. Aporta, S. Gearheard, G. J. Laidler, \& L. Kielsen Holm (Eds.), Siku: Knowing our ice (pp. 445-455). New York: Springer.

Canadian Environmental Protection Act, 1999, SC 1999, c 33.

Canadian Navigable Waters Act, RSC 1985, c N-22.

Chénier, R., Abado, L., Sabourin, O., \& Tardif, L. (2017). Northern marine transportation corridors: Creation and analysis of northern marine traffic routes in Canadian waters. Transactions in GIS, 21(6), 1085-1097.

CSA. 2001. Canada Shipping Act, 2001, SC 2001, c 26.

Dowsley, M. (2015). Identity and the evolving relationship between Inuit women and the land in the eastern Canadian Arctic. Polar Record, 51(260), 536-549. 
Gibson, J. J. (1979). The ecological approach to visual perception. Boston: Houghton Miffli.

Government of Canada. (2019). Protecting our coasts: Oceans Protection Plan. https://www.tc.gc. ca/en/campaigns/protecting-coasts.html. Accessed 21 Oct 2019.

Heyes, S. (2007). Inuit knowledge and perceptions of the land-water interface. $\mathrm{PhD}$ dissertation. McGill University.

Huntington, H. P., Gearheard, S., \& Kielsen Holm, L. (2010). The power of multiple perspectives: Behind the scenes of the Siku-Inuit-Hila project. In I. Krupnik, C. Aporta, S. Gearheard, G. J. Laidler, \& L. Kielsen Holm (Eds.), Siku: Knowing our ice (pp. 257-274). New York: Springer.

Ingold, T. (2000). The perception of the environment. London: Routledge.

Kielsen Holm, L. (2010). Sila-Inuk: Study of the impacts of climate change in Greenland. In I. Krupnik, C. Aporta, S. Gearheard, G. J. Laidler, \& L. Kielsen Holm (Eds.), Siku: Knowing our ice (pp. 145-162). New York: Springer.

Krupnik, I., Aporta, C., Gearheard, S., Laidler, G. J., \& Kielsen Holm, L. (Eds.). (2010). Siku: Knowing our ice, documenting Inuit Sea ice knowledge and use. New York: Springer.

Laidler, G. J. (2006). Inuit and scientific perspectives on the relationship between sea ice and climate change: The ideal complement? Climatic Change, 78, 407-444.

Laidler, G. J. (2007). Ice, through Inuit eyes: Characterizing the importance of sea ice processes, use, and change around three Nunavut communities. PhD dissertation. University of Toronto.

Lasserre, F., \& Pelletier, S. (2011). Polar seaways? Maritime transport in the Arctic: An analysis of shipowners' intentions. Journal of Transport Geography, 19(6), 1465-1473.

Lasserre, F., Beveridge, L., Fournier, M., Têtu, P. L., \& Huang, L. (2016). Polar seaways? Maritime transport in the Arctic: An analysis of shipowners' intentions II. Journal of Transport Geography, 57, 105-114.

Migratory Birds Convention Act, 1994, SC 1994, c 22 (Canada).

Oceans Act, SC 1996, c 31 (Canada).

Office of the Prime Minister. (2016). United States-Canada Joint Arctic Leaders' Statement. https://pm.gc.ca/en/news/statements/2016/12/20/united-states-canada-joint-arctic-leadersstatement. Accessed 21 Oct 2019.

Pizzolato, L., Howell, S., Dawson, J., Copland, L., Derksen, C., \& Johnston, M. (2013). Climate change adaptation assessment for transportation in Arctic waters (CATAW) scoping study: Summary report. Ottawa: Transport Canada.

Polar Code. (2014/15). International Code for Ships Operating in Polar Waters (Polar Code), IMO Resolution MSC.385(94) (21 November 2014, effective 1 January 2017); Amendments to the International Convention for the Safety of Life at Sea 1974, IMO Resolution MSC.386(94) (21 November 2014, effective 1 January 2017); Amendments to MARPOL Annexes I, II, IV and V, IMO Resolution MEPC.265(68) (15 May 2015, effective 1 January 2017). http://www.imo. org/en/MediaCentre/HotTopics/polar/Documents/POLAR\%20CODE\%20TEXT\%20AS\%20 ADOPTED.pdf. Accessed 17 Oct 2019.

PPR (Sub-Committee on Prevention, Preparedness and Response). (2019). Report to the Marine Environment Protection Committee, IMO Doc. PPR 6/20 (19 March 2019).

Rasing, W. (2017). Too many people: Contact, disorder, change in an Inuit society, 1822-2015 (2nd ed.). Iqaluit: Nunavut Arctic College Media.

Sable, T., Howell, G., Wilson, D., \& Penashue, P. (2006). The Ashkui project: Linking western science and Innu environmental knowledge in creating a sustainable environment. In P. Sillitoe (Ed.), Local science vs global knowledge: Approaches to indigenous knowledge in international development (pp. 109-127). Oxford/New York: Berghahn Books.

Searles, E. (2009). Inuit identity in the Canadian Arctic. Ethnology, 47(4), 239-255.

Searles, E. (2010). Placing identity: Town, land, and authenticity in Nunavut, Canada. Acta Borealia, 27(2), 151-166.

Shipping Safety Control Zones Order. CRC, c 356 (Canada).

Steinberg, P. E. (1999). Navigating to multiple horizons: Toward a geography of ocean-space. The Professional Geographer, 51(3), 366-375. 
Steinberg, P. E., \& Peters, K. (2015). Wet ontologies, fluid spaces: Giving depth to volume through oceanic thinking. Society and Space, 33, 247-264.

Stephenson, J., \& Moller, H. (2009). Cross-cultural environmental research and management: Challenges and progress. Journal of the Royal Society of New Zealand, 39(4), 139-149.

Tester, F. J., \& Irniq, P. (2008). Inuit Qaujimajatuqangit: Social history, politics and the practice of resistance. Arctic, 61(1), 48-61.

Transport Canada. (2017). Transport Canada departmental plan 2017-18. http://www.tc.gc.ca/ media/documents/corporate-services/transport_canada_departmental_plan.pdf. Accessed 20 Oct 2019.

Transport Canada. (2018). Arctic Ice Regime Shipping System (AIRSS) standard. TP 12259.

Transport Canada. (2019a). Draft national framework: Proactive vessel management. https://www. tc.gc.ca/documents/Draft_Framework_for_PVM_-_accessible.pdf. Accessed 21 Oct 2019.

Transport Canada. (2019b). Protecting the North Atlantic right whale: New speed restriction measures in the Gulf of St. Lawrence (amendments 2019-08-02). Ship Safety Bulletin No. 11/2019. https://www.tc.gc.ca/eng/marinesafety/bulletins-2019-11-eng.htm. Accessed 21 Oct 2019.

Trippett, F. (2000). Towards a broad-based precautionary principle in law and policy: A functional role for indigenous knowledge systems (TEK) within decision-making structures. LLM thesis. Dalhousie University.

Tyrrell, M. (2005). Inuit perception, knowledge and use of the sea in Arviat, Nunavut. PhD dissertation. University of Aberdeen.

UNCLOS. (1982). United Nations Convention on the Law of the Sea (10 December 1982, entered into force 16 November 1994), 1833 UNTS 396.

Viveiros de Castro, E. (2004). Perspectival anthropology and the method of controlled equivocation. Tipiti: Journal of the Society for the Anthropology of Lowland South America, 2(1), 3-22.

Whitridge, P. (2004). Landscapes, houses, bodies, things: "Place" and the archaeology of Inuit imaginaries. Journal of Archaeological Method and Theory, 11(2), 213-250.

Wisniewski, J. (2010). Knowings about Sigu: Kigiqtaamiut hunting as an experiential pedagogy. In I. Krupnik, C. Aporta, S. Gearheard, G. J. Laidler, \& L. Kielsen Holm (Eds.), Siku: Knowing our ice (pp. 275-294). New York: Springer.

Open Access This chapter is licensed under the terms of the Creative Commons Attribution 4.0 International License (http://creativecommons.org/licenses/by/4.0/), which permits use, sharing, adaptation, distribution and reproduction in any medium or format, as long as you give appropriate credit to the original author(s) and the source, provide a link to the Creative Commons license and indicate if changes were made.

The images or other third party material in this chapter are included in the chapter's Creative Commons license, unless indicated otherwise in a credit line to the material. If material is not included in the chapter's Creative Commons license and your intended use is not permitted by statutory regulation or exceeds the permitted use, you will need to obtain permission directly from the copyright holder.

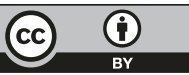

